\title{
The Biogenesis of Lysosomes and Lysosome-Related Organelles
}

\author{
J. Paul Luzio ${ }^{1}$, Yvonne Hackmann², Nele M.G. Dieckmann², and Gillian M. Griffiths ${ }^{2}$ \\ ${ }^{1}$ Department of Clinical Biochemistry, Cambridge Institute for Medical Research, University of Cambridge, \\ Cambridge Biomedical Campus, Cambridge CB2 OXY, United Kingdom \\ ${ }^{2}$ Department of Medicine, Cambridge Institute for Medical Research, University of Cambridge, Cambridge \\ Biomedical Campus, Cambridge CB2 OXY, United Kingdom \\ Correspondence: jpl10@cam.ac.uk
}

Lysosomes were once considered the end point of endocytosis, simply used for macromolecule degradation. They are now recognized to be dynamic organelles, able to fuse with a variety of targets and to be re-formed after fusion events. They are also now known to be the site of nutrient sensing and signaling to the cell nucleus. In addition, lysosomes are secretory organelles, with specialized machinery for regulated secretion of proteins in some cell types. The biogenesis of lysosomes and lysosome-related organelles is discussed, taking into account their dynamic nature and multiple roles.

\section{WHAT IS A LYSOSOME?}

Leont ysos ysosomes are membrane-bound organelles containing more than 50 acid hydrolases that function in the degradation of macromolecules delivered via endocytic, phagocytic, and autophagic pathways. The discovery of lysosomes by Christian De Duve was an early triumph of subcellular fractionation, after it was found that the measured activity of acid hydrolases greatly increased following exposure of subcellular fractions to hypotonic media, detergents, or other insults to membrane integrity (Bainton 1981; de Duve 2005). Electron microscopy subsequently showed that lysosomes constitute up to $5 \%$ of the intracellular volume of animal cells and are heterogeneous in size and morphology, often with electron-dense content and sometimes multilamellar membrane whorls (see Klumperman and Raposo 2014). Lysosomes are distinguished from late endosomes by the absence of mannose-6-phosphate receptors (MPRs) (Brown et al. 1986). There has recently been a resurgence of interest in lysosomes because of data showing that they can function as signaling organelles sensing nutrient availability and activating a lysosometo-nucleus signaling pathway that mediates the starvation response and regulates energy metabolism (Settembre et al. 2013). In addition, regulated exocytosis of conventional lysosomes has been discovered and is an important property of many lysosome-related organelles (LROs), a group of functionally diverse, cell-type-specific organelles that share many features with lysosomes and are discussed in greater detail below.

Editors: Sandra L. Schmid, Alexander Sorkin, and Marino Zerial

Additional Perspectives on Endocytosis available at www.cshperspectives.org

Copyright (C) 2014 Cold Spring Harbor Laboratory Press; all rights reserved; doi: 10.1101/cshperspect.a016840

Cite this article as Cold Spring Harb Perspect Biol 2014;6:a016840 
J.P. Luzio et al.

The passage of macromolecules through the endocytic pathway to lysosomes has been well described (Luzio et al. 2007; Woodman and Futter 2008; Huotari and Helenius 2011). Whereas traffic through early endosomes to late endosomes/multivesicular bodies (MVBs) is most easily considered as a maturation process, delivery of lysosomal hydrolases involves kiss-andrun events and complete fusions between late endosomes and lysosomes. These fusion events were inferred from electron microscopy (Futter et al. 1996; Bright et al. 1997) as well as cell-free content mixing assays (Mullock et al. 1994) and shown directly with live cell microscopy (Bright et al. 2005; Gan et al. 2009). A consequence of fusion is the formation of the "endolysosome," a hybrid organelle with properties intermediate between the late endosome and the lysosome. Thus, for example, although late endosomes are thought to be relatively depleted in MPRs when ready for fusion with lysosomes (Hirst et al. 1998), endolysosomes do contain MPRs and are therefore still prelysosomal compartments as classically defined (Griffiths et al.
1988). Lysosomes are then re-formed by maturation of endolysosomes (Fig. 1). Although historically lysosomes have been thought of as the terminal degradative compartment of the endocytic pathway, it is likely that most degradation occurs in endolysosomes when they are formed and as they go through the process of re-forming lysosomes. Indeed, the classical electrondense lysosome may be more akin to a secretory granule, storing hydrolases ready to be delivered to the site of macromolecule degradation when fusion with late endosomes occurs. The very dynamic nature of the terminal compartments of the endocytic pathway has to be taken into account when considering lysosome biogenesis because many newly synthesized lysosomal proteins have been shown to be first delivered to endosomes.

\section{LYSOSOME FUSION AND RE-FORMATION}

Experimental systems have been developed to study the molecular machinery of cargo delivery to lysosomes from endocytic, phagocytic, and

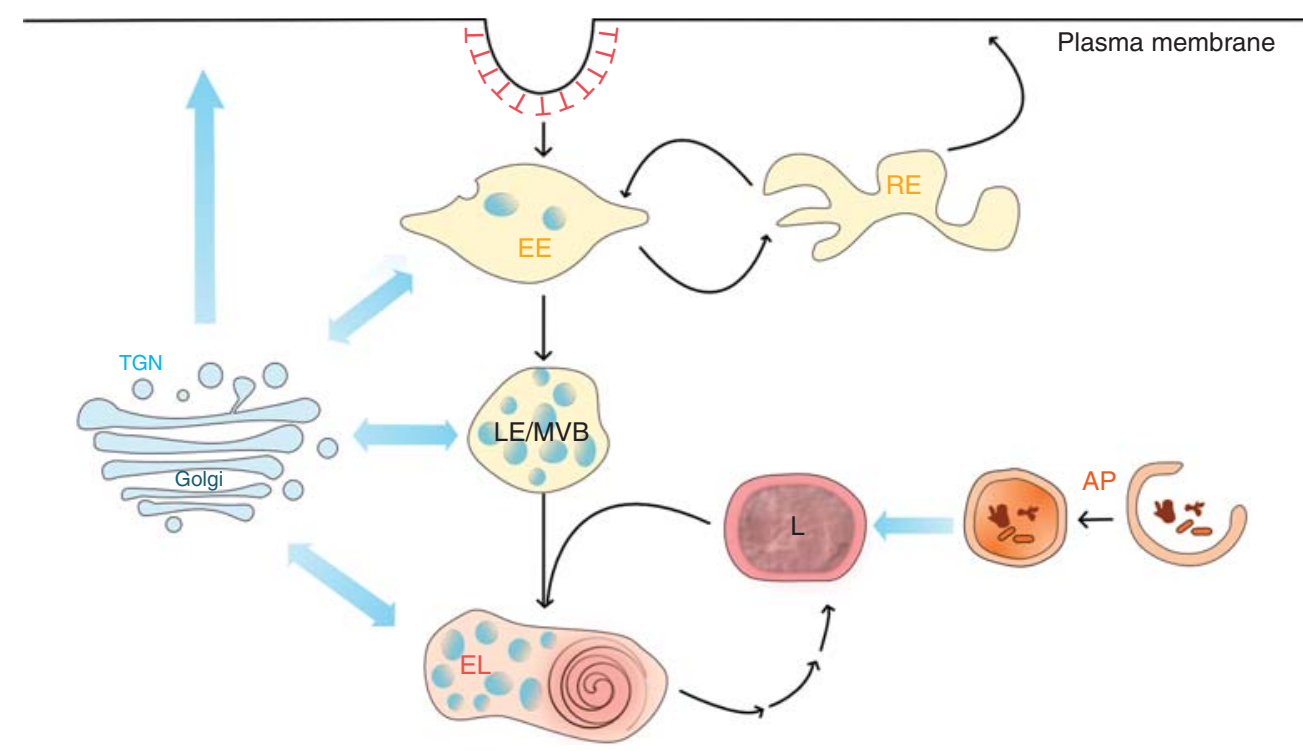

Figure 1. Delivery to lysosomes. Lysosomes (L) are terminal compartments of the endocytic and autophagic pathways (AP). Newly synthesized lysosomal proteins are delivered to them from the trans-Golgi network (TGN) via early endosomes (EE), recycling endosomes (RE), and late endosomes/multivesicular bodies (LE/MVB). Following lysosome fusion with late endosomes to form an endolysosome (EL), lysosomes are re-formed by a maturation process. 
autophagic pathways in mammalian cells. Proteins required for fusion of late endosomes with lysosomes have been identified using a variety of approaches including inhibitors in permeabilized cell and cell-free assays together with overexpression and RNA interference/knockdown studies in cultured cells. The fusion machinery comprises cytosolic factors and trans-SNARE (soluble $\mathrm{N}$-ethylmaleimide-sensitive factor-attachment protein receptor) complexes, but for efficient fusion there is also a need for $\mathrm{Ca}^{2+}$, released from the lumen of the fusing organelles (Fig. 2) (Mullock et al. 1998; Pryor et al. 2000; Ward et al. 2000b). The cytosolic factors include NSF ( $N$-ethyl-maleimide-sensitive factor), soluble NSF-attachment proteins, the small GTPase Rab7 (Vanlandingham and Ceresa 2009), and tethers made up of the HOPS (homotypic fusion and vacuole protein sorting) proteins (Balderhaar and Ungermann 2013; Pols et al. 2013a). Antibody inhibition studies in a cell-free system identified the trans-SNARE complex for heterotypic fusion of late endosomes with lysosomes as comprising syntaxin 7, Vti1b, syntaxin 8, and VAMP7 (vesicle-associated membrane protein 7) (Pryor et al. 2004).
This differs from the trans-SNARE complex required for homotypic late endosome fusion in which VAMP8 replaces VAMP7 (Antonin et al. 2000). VAMP7 is also required for lysosome fusion with the plasma membrane (Rao et al. 2004) and has been implicated in the fusion of lysosomes with phagosomes (Braun et al. 2004) and with autophagosomes (Fader et al. 2009). Although it would appear that VAMP7 is important for a variety of lysosomal fusion events, the lack of obvious developmental defects or lysosomal phenotype in VAMP7-knockout mice (Sato et al. 2011; Danglot et al. 2012) and the inability to block endocytic delivery to lysosomes by VAMP7 knockdown in cultured cells (Pols et al. 2013a) suggests, at the very least, caution in overinterpreting its likely importance for lysosome fusion.

The fusion of late endosomes with lysosomes would consume both organelles if no recovery process occurred, and thus lysosome re-formation from endolysosomes is a necessary, although poorly understood process. Lysosomes have a more-condensed lumenal content than endolysosomes, and an in vitro study has shown that content condensation requires a

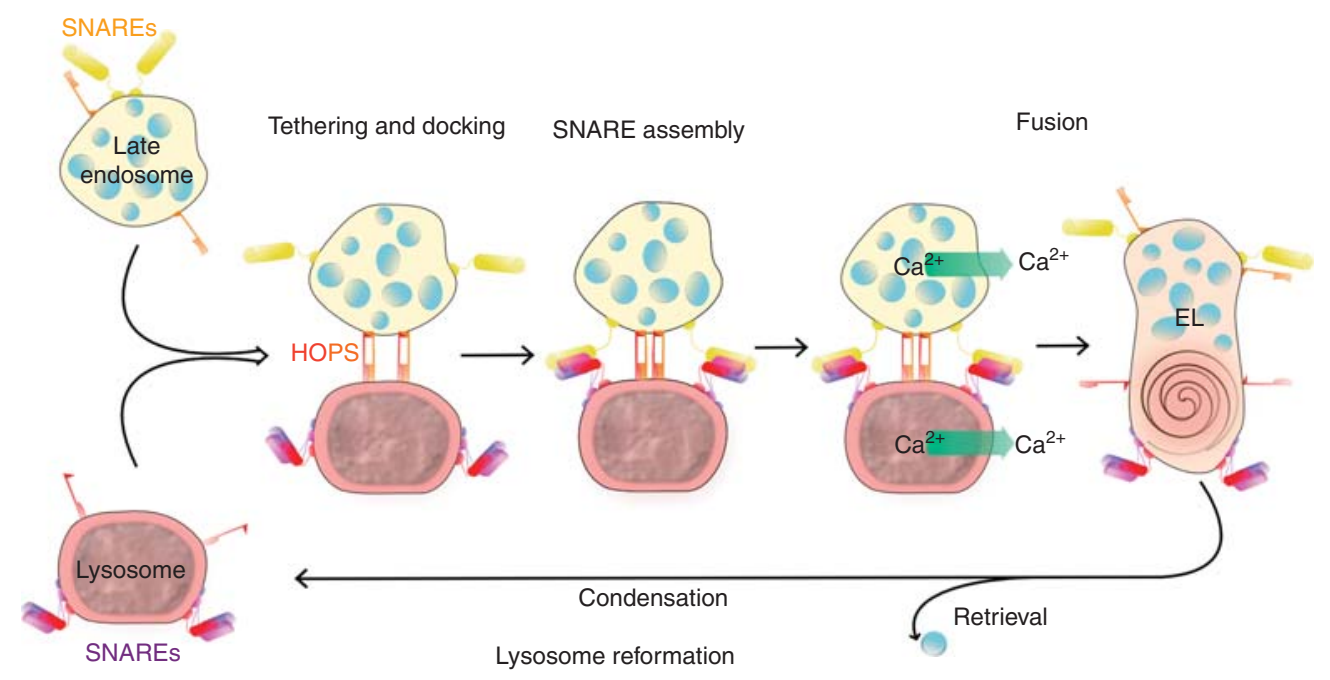

Figure 2. The molecular machinery of heterotypic fusion of lysosomes with late endosomes. Fusion requires tethering and docking (using HOPS proteins), trans-SNARE assembly, and lipid bilayer fusion steps. Following fusion, lysosomes can be re-formed from endolysosomes (EL) by a maturation process involving content condensation and retrieval pathways removing endosomal membrane proteins and recycling SNAREs. 
J.P. Luzio et al.

proton-pumping ATPase and lumenal $\mathrm{Ca}^{2+}$ (Pryor et al. 2000). Thus, the V-ATPase in the lysosomal membrane appears not only to be responsible for the well-described function of creating the acidic environment for macromolecule hydrolysis by lysosomal hydrolases, but also to generate dense-core lysosomes (Hirota et al. 2004). During the re-formation of lysosomes from endolysosomes, there is also membrane retrieval to remove endosomal membrane proteins and recycle SNAREs. Consistent with this, live-cell microscopy has shown vesicular tubular structures leaving endolysosomes after endosome-lysosome fusion (Bright et al. 2005). In the re-formation of lysosomes from autolysosomes formed by autophagosome-lysosome fusion (Jahreiss et al. 2008), protolysosomal tubules extrude and mature into lysosomes, the process being regulated by mTOR (mammalian target of rapamycin) (Yu et al. 2010).

Some additional clues as to the machinery of lysosome re-formation have come from observations of cells from patients with lysosomal storage diseases. These are rare, inherited genetic defects, in many cases causing deficiencies in specific lysosomal acid hydrolases but in others resulting in defects in lysosomal membrane proteins or nonenzymatic soluble lysosomal proteins. Cells from such patients contain membrane-bound heterogeneous storage lesions, most probably abnormal endolysosomes/autolysosomes, filled with different contents in different diseases (Platt et al. 2012). The lack of efficient degradation of macromolecules may itself prevent lysosome re-formation (Bright et al. 1997; Schmid et al. 1999) and also reduce the efficiency of fusion via effects on membrane cholesterol (Fraldi et al. 2010). A defect in lysosome re-formation from endolysosomes has been proposed as the primary cellular defect in Niemann-Pick type-C2-deficient cells, contrasting with a defect in endosome-lysosome fusion in Niemann-Pick type-C1-deficient cells, the latter likely being a consequence of altered luminal $\mathrm{Ca}^{2+}$ content (Lloyd-Evans et al. 2008). The mechanism by which Niemann-Pick type C2 may function to prevent lysosome re-formation is not known. Similarly, in Chédiak-Higashi syndrome, the absence of the protein Lyst (lysosomal trafficking regulator) does not affect lysosome fusion but has an effect on fission by an unknown mechanism (Durchfort et al. 2012). Finally, the absence of the lysosomal cation transporter mucolipin-1 in cells from patients with mucolipidosis type IV has been suggested to result in a failure to reform lysosomes from endolysosomes (Treusch et al. 2004).

\section{DELIVERY OF NEWLY SYNTHESIZED PROTEINS TO LYSOSOMES}

It has only recently become apparent that the biosynthesis of lysosomes entails the coordinated transcription of genes encoding lysosomal proteins. Many genes encoding lysosomal enzymes and membrane proteins have a palindromic 10-bp (base pair) GTCACGTGAC motif in their promoter region that can bind transcription factor EB (TFEB) and has been named the coordinated lysosomal expression and regulation (CLEAR) element (Sardiello et al. 2009). Nonactive TFEB is highly phosphorylated and is bound to the cytosolic surface of lysosomes, but under specific conditions, such as starvation or lysosome dysfunction, it becomes dephosphorylated and is rapidly translocated to the nucleus (for review, see Settembre et al. 2013; see also Settembre and Ballabio 2014), resulting in up-regulation of synthesis of acid hydrolases and other proteins found within lysosomes as well as lysosomal membrane proteins.

The pathway by which most of the newly synthesized acid hydrolases are delivered to lysosomes in mammalian cells has been known for many years (for review, see Kornfeld and Mellman 1989; Ghosh et al. 2003; Braulke and Bonifacino 2009; Saftig and Klumperman 2009). Following insertion into the lumen of the endoplasmic reticulum, signal sequence cleavage, and core glycosylation, they traffic to the Golgi complex, where unmasking in the cis-Golgi reveals a lysosomal-targeting mannose-6-phosphate sugar. When they reach the trans-Golgi network (TGN), they are recruited by one of two MPRs and trafficked to endo- 
somes, where they dissociate from the receptors as a result of the acidic luminal $\mathrm{pH}$, allowing the receptors to recycle to the TGN. The acid hydrolases can then move on to endolysosomes and lysosomes as described above and can be further modified, leading to enzyme activation. Considerable effort has gone into understanding the molecular machinery of MPR traffic. In the TGN the cargo-loaded MPRs are sorted into clathrin-coated vesicles for transport to endosomes, using the adaptors AP1 and GGAs (Golgi-localized, $\gamma$-ear-containing, ADP ribosylation factor binding proteins) that interact with sequence motifs in the cytosolic tails of the MPRs. The route back from endosomes to the TGN for the empty MPRs requires the retromer machinery (for review, see Attar and Cullen 2010). Although the MPR route is the most important for delivery of soluble luminal proteins to the lysosome, it cannot be the only route. This is apparent because in patients with I-cell disease, lysosomal hydrolases do not acquire mannose-6-phosphate tags because of a deficiency in $\mathrm{N}$-acetylglucosamine-phosphotransferase activity, but in some cells including hepatocytes and lymphocytes a significant proportion of newly synthesized acid hydrolases does reach lysosomes. In addition, some MPRindependent routes for targeting lysosomal enzymes have been described (Coutinho et al. 2012). Thus, for example, $\beta$-glucocerebrosidase is delivered to lysosomes using the lysosomal integral membrane protein LIMP-2 as the trafficking receptor.

The limiting membrane of the lysosome contains more than 100 proteins including the $\mathrm{V}$-ATPase required to ensure an acidic milieu for lysosomal hydrolase function and many transporters (Schwake et al. 2013). The most abundant type 1 transmembrane proteins are LAMP1 and LAMP2, which have been suggested to make up $\sim 50 \%$ of lysosomal membrane protein content. Delivery of newly synthesized integral membrane proteins to the lysosome does not require tagging with mannose- 6 -phosphate (for review, see Andrews 2002; Braulke and Bonifacino 2009; Saftig and Klumperman 2009; Schwake et al. 2013). The delivery routes of the lysosomal membrane proteins most studied have historically been divided into direct and indirect routes dependent on whether traffic from the TGN to the lysosome passes via the plasma membrane (the indirect route), although this may differ between cell types for the same protein. To date, the best-described sequence motifs that target membrane proteins from the TGN to lysosomes have been identified as of the YXXØ or [DE]XXXL[LI] types, which also function as endocytic signals. However, delivery to lysosomes is favored by some specific features such as a glycine residue immediately before the YXX $\varnothing$ residues, and it is notable that such sequence motifs are usually close to the transmembrane domain and often toward the end of short cytosolic tails. When lysosomal membrane proteins containing such sequence motifs are delivered to lysosomes via the indirect route, binding to the AP2 clathrin adaptor at the plasma membrane enables efficient sorting into clathrin-coated vesicles for delivery into the endosomal system. These sequence motifs also bind efficiently to the clathrin adaptor AP3, which is mainly localized on tubulovesicular early sorting/recycling endosomes and ensures delivery to endolysosomes/lysosomes. Although lysosomal membrane proteins have been observed in AP1/clathrin-positive vesicles derived from the TGN, recent work has identified a direct route from the TGN to late endosomes mediated by a specialized class of uncoated vesicles (Pols et al. 2013b). These lysosome membrane protein carriers were shown not to contain MPRs or endocytic markers but do contain the HOPS protein hVps41 and VAMP7. Knockdown of either hVps41 or VAMP7 resulted in accumulation of the carriers. Relatively little is known about how lysosomal SNAREs are delivered, although these are essential to the creation of a functional lysosome. Like most SNAREs, VAMP7 does not contain classical tyrosine- or dileucine-based sorting/targeting motifs. However, its longin domain is available to interact with trafficking machinery when the VAMP7 is in a cis-SNARE complex following membrane fusion. The longin domain has been shown to bind to Hrb, a protein that interacts with clathrin and AP2, and also to AP3 (Kent et al. 2012). These interactions are impor- 
J.P. Luzio et al.

tant in retrieving and delivering VAMP7 to late endocytic compartments.

\section{SECRETORY LYSOSOMES: WHAT MAKES A LYSOSOME A SECRETORY ORGANELLE?}

Although lysosomes are not classical secretory organelles, there are now many lines of evidence that support the idea that lysosomes in virtually all cell types can undergo secretion at the plasma membrane. Lysosomal secretion has been implicated in plasma membrane repair and defense against parasites, as well as gliotransmitter and ATP release from astrocytes (Reddy et al. 2001; Andrews 2002; Jaiswal et al. 2002; Zhang et al. 2007; Li et al. 2008; Divangahi et al. 2009; Laulagnier et al. 2011). Secretion of conventional lysosomes appears to involve the release of a relatively small proportion of lysosomes, which are likely close to the plasma membrane. It is calcium dependent and has been shown to involve Synaptotagmin VII and the SNARE proteins VAMP7, SNAP23 (23-kDa-synaptosomeassociated protein), and syntaxin 4 (Rao et al. 2004). Recent studies have shown that TFEB controls lysosomal secretion at the plasma membrane, triggering translocation to and release at the plasma membrane, although the precise mechanisms for this are not yet understood (Medina et al. 2011). In some cellular models of lysosomal storage diseases, overexpression of TFEB has been shown to lead to an increase in lysosomal docking and exocytosis, a decrease in lysosomal size, and consequently clearance of accumulated metabolites (Medina et al. 2011; Spampanato et al. 2013).

Although there is now good evidence that conventional lysosomes can fuse with the plasma membrane when triggered by injury or other stimuli, some cell types have specialized secretory lysosomes, with specialized mechanisms for delivery to the plasma membrane and exocytosis. In these cell types, the lysosomes contain proteins destined for secretion in addition to the lysosomal hydrolases required for protein degradation within the cell. These specialized lysosomes are known as "secretory lysosomes" or "lysosome-related organelles" (LROs).

\section{SECRETORY LYSOSOMES AND LYSOSOME- RELATED ORGANELLES}

What makes a lysosome become specialized for secretion? Cells with secretory lysosomes target additional secretory proteins to the conventional lysosomes and have a mechanism for movement to the plasma membrane that involves recruiting additional proteins to their outer membrane for movement and fusion. In these cell types, which include CTL, mast cells, and osteoclasts, secretory lysosome biogenesis is remarkably similar to the biogenesis of conventional lysosomes. In other cell types that use LROs, such as melanocytes and endothelial cells, conventional lysosomes also exist, and LRO biogenesis diverges from the pathway used by conventional lysosomes. Proteins destined for secretion are targeted to LROs for the specialized secretory pathway (Fig. 3).

Many cell types derived from the hematopoietic system including immune cells and osteoclasts use lysosomal secretion as a mechanism for specialized secretion, with different effector proteins packaged for release. Melanocytes and endothelial cells are the best-characterized nonhematopoietic cell types that use a very closely related mechanism for formation and fusion of melanosomes and Weibel-Palade bodies (WPBs), respectively. The former secrete melanin, which is key for pigmentation, whereas the contents released from Weibel-Palade bodies play a key role in blood clotting. Additional cell types have more recently been added to this list including astrocytes, catecholaminergic neurons, and pulmonary type II cells (Weaver et al. 2002; Tribl et al. 2006; Zhang et al. 2007; Li et al. 2008).

\section{TRAFFICKING SECRETORY PROTEINS TO LYSOSOMES}

The trafficking of proteins to melanocytes has been recently reviewed (Raposo et al. 2007; Sitaram and Marks 2012; Marks et al. 2013). This review focuses on summarizing the mechanisms for sorting and secretion of the secretory lysosomes found in cytotoxic $\mathrm{T}$ lymphocytes (CTLs) and natural killer (NK) cells. One of 
Lysosome Biogenesis
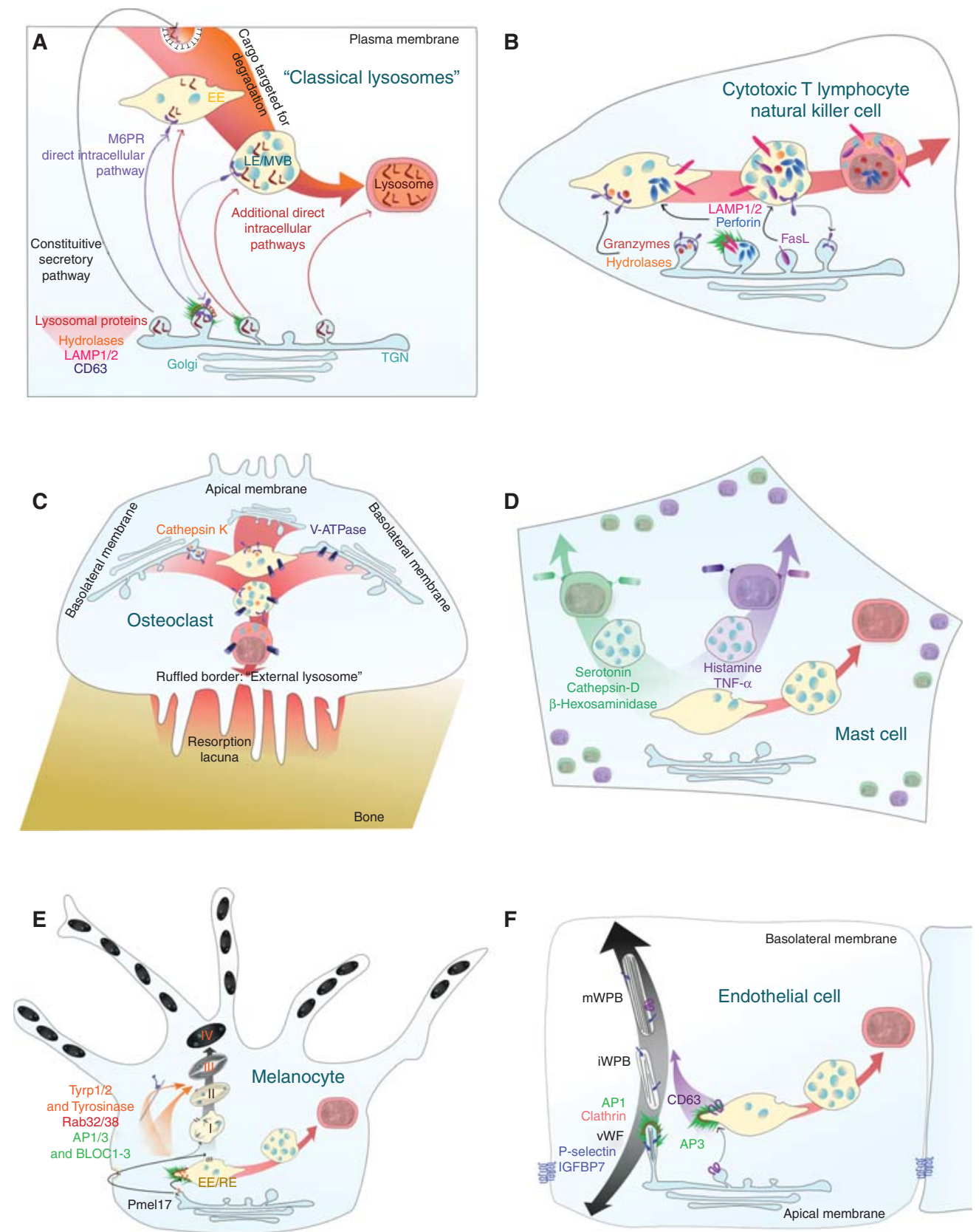

Figure 3. Biogenesis of secretory lysosomes and LROs. Schematic showing biogenesis of $(A)$ conventional lysosome via early endosome (EE), late endosome/multivesicular bodies (LE/MVB) compared with the pathways used in the biogenesis of $(B)$ secretory lysosomes in CTL, and $(C)$ osteoclasts in which all lysosomes appear to be secretory lysosomes. $(D)$ In mast cells, conventional lysosomes seem to coexist with granules containing different contents. $(E)$ In melanocytes, and $(F)$ endothelial cells, LROs are derived via a linked but distinct pathway from conventional lysosomes. 
J.P. Luzio et al.

the key proteins stored within secretory lysosomes of CTL and NK cells is perforin, a multidomain protein crucial for CTL and NK cell effector function. Perforin resembles the C9 component of the membrane-attack complex because it oligomerizes at neutral $\mathrm{pH}$ and in the presence of $\mathrm{Ca}^{2+}$ ions, thus creating 50-300 ̊ pores across lipid bilayers (Henkart et al. 1984, 1986; Podack et al. 1985; Lowrey et al. 1989; Baran et al. 2009; Law et al. 2010). The other set of proteins secreted from the specialized lysosomes in CTL is a series of serine proteases, termed granzymes, that cleave caspases once in the target cell and trigger rapid apoptosis.

Some of the early research on the targeting of these proteins revealed that perforin and granzymes followed very different trafficking pathways (Burkhardt et al. 1989). Granzymes are modified by a mannose-6-phosphate just like lysosomal hydrolases, and their sorting is disrupted when the phosphotransferase that makes this modification is absent in mucolipidosis II (I-cell disease) (Griffiths and Isaaz 1993). However, perforin is not modified with a mannose-6-phosphate, receiving only complex glycans, and cannot use the MPR pathway (Burkhardt et al. 1989; Uellner et al. 1997). Precisely how perforin is trafficked to the secretory lysosome remains something of a mystery, because disruption of the protein either by truncation or removal of the glycans results in misfolding and degradation when expressed in cells (Uellner et al. 1997; Brennan et al. 2011). Most recently it has been suggested that loss of either adaptin $\gamma$ (AP1 subunit) or LAMP1 blocks perforin trafficking to the granules by disrupting granule movement rather than acting as a trafficking receptor (Krzewski et al. 2013).

The transmembrane protein Fas ligand is also sorted to the secretory lysosomes of CTLs (Bossi and Griffiths 1999; Blott et al. 2001; Kojima et al. 2002). The critical sorting motif is a proline-rich domain in the cytoplasmic tail of Fas ligand, which is able to bind the kinase Fgr and phosphorylate Fas ligand. Importantly the proline-rich domain is flanked by a dileucine motif that can be ubiquitinated and facili- tate sorting into intraluminal vesicles (Blott et al. 2001; Zuccato et al. 2007). In this way, Fas ligand makes use of the ubiquitination pathway into MVBs and the lysosome, not for degradation but rather for storage and secretion. What appears to be unusual is that the phosphorylation is not required for the mono-ubiquitination of Fas ligand, but deletion of either the tyrosines or the lysines disrupts internalization into intraluminal vesicles. Although the localization on intraluminal vesicles has only been shown when Fas ligand is expressed in mast cells to date (Zuccato et al. 2007), it seems likely that these sorting motifs will sort Fas ligand to the same localization in CTLs and NKs. Screens for proteins binding to the cytoplasmic tail of Fas ligand have identified many binding partners, some of which have been suggested to play a role in Fas ligand targeting to the lysosome (Baum et al. 2005; Thornhill et al. 2007).

Other cell types exploit related pathways to traffic proteins to LROs: Acidic hydrolases stored within LROs of osteoclasts are transported by the MPR; AP1 is linked to tyrosinase, TYRP-1, and Rab32/38 trafficking in melanocytes (acting together with AP3; see below) and plays a major role in the formation of WPBs in endothelial cells; the BLOC complexes (BLOC$1,-2$, and -3 ) are crucial for melanosome formation and maturation (Marks et al. 2013); the tetraspanin CD63 acts as a platform for elastase recruitment in neutrophils; and other proteins (von Willebrand factor, proteins in azurophilic granules of neutrophils) aggregate, thus adopting distinct structures that may initiate formation of an LRO around them (Harrison-Lavoie et al. 2006; Doyle et al. 2011).

\section{THE COMMON MECHANISMS: LESSONS FROM IMMUNODEFICIENCIES}

Our knowledge about how lytic granules are formed, polarized, and secreted at the immunological synapse was substantially advanced by the study of the molecular mechanisms behind human immunodeficiencies, namely, familial haemophagocytic lymphohistiocytosis (FHL), Griscelli syndrome, and Hermansky-Pudlak and Chédiak-Higashi syndromes. These au- 
tosomal-recessive diseases share the clinical phenotype of ongoing infections and hyperactivation of the entire immune system, which often cause fatality of the affected individual. Griscelli, Hermansky-Pudlak, and ChédiakHigashi syndromes also give rise to albinism. This provided important information linking the biogenesis of the secretory lysosomes from immune cells and the LROs from melanocytes and endothelial cells.

Chédiak-Higashi syndrome (CHS) is phenotypically marked by an increase in lysosome size in all cell types. However, only the cell types with secretory lysosomes or LROs are functionally affected, suggesting that it is the secretory step that is selectively affected. Mutations in CHS have been mapped to Lyst (or beige in mouse), an $\sim 430-\mathrm{kDa}$ protein that contains Heat domains, a WD40 repeat, and is a member of the BEACH (beige and Chédiak) protein family. Lytic granules in CTLs derived from CHS patients function normally during protein degradation but fail to be secreted upon target cell recognition (Baetz et al. 1995; Ward et al. 2000a). Lyst interacts with several SNARE proteins, either directly or potentially via the CALM (clathrin-assembly lymphoid myeloid leukemia) protein, which is involved in the recycling of SNAREs from the plasma membrane (Miller et al. 2011), signaling protein 14-3-3, casein kinase II, and Hrs. The finding that secretory lysosomes in CTL from CHS patients retain ER-specific membrane proteins and display autophagic inclusions might be indicative of the finding that Lyst deficiency results in normal vesicle fusion but impaired fission from lysosomes (Miller et al. 2011; Durchfort et al. 2012). Exactly why these granules fail to secrete from CTLs and from melanocytes is not known. One possibility, which has not been ruled out, is that the granules are simply too large to fuse properly.

The AP3 adaptor complex is also required not only in CTLs but also in melanocytes, endothelial cells, and platelets, although the exact mechanisms seem to differ between CTLs and melanocytes. Mutations in the $\beta 3 \mathrm{~A}$ subunit of the AP3 heterotetramer cause HermanskyPudlak syndrome type 2 (HPS2) and are pre- dominantly associated with partial albinism and platelet dysfunction, but also immunodeficiency (Hermansky and Pudlak 1959; Schmid et al. 1999; Huizing et al. 2002). Although AP3 is crucial for sorting of tyrosinase- and melanin-processing proteins into melanosomes (Theos et al. 2005), thus explaining why loss of AP3 causes albinism, the mechanism by which CTLs are affected is only partially understood. However, CTLs from an HPS2 patient display an increase in tubulovesicular endosomes and also fail to polarize toward the immunological synapse. Patients with other mutations in the $\beta 3 \mathrm{~A}$ subunit, however, show only a mild loss of secretion by comparison (Clark et al. 2003; Wenham et al. 2010). Because AP3 is known to be crucial for selection of cargo into late endosomes/lysosomes (Kent et al. 2012), it seems likely that AP3 mediates trafficking of a microtubule motor protein or its adaptor to the surface of secretory lysosomes in CTLs.

Other adaptor proteins also play a critical role during LRO formation. In endothelial cells, AP1 mediates the formation of Weibel-Palade bodies (Lui-Roberts et al. 2005); however, besides a potential link to perforin delivery to secretory lysosomes, not much is known about the function of AP1 in CTLs (Krzewski et al. 2013). Interestingly, AP1, AP2, and the AP1 recruitment factor Gadkin, but not AP3, are also crucial for classical lysosome secretion (Laulagnier et al. 2011), suggesting that involvement of different adaptor protein complexes marks the selective trafficking of proteins to either LROs or lysosomes.

\section{SECRETION AT THE IMMUNOLOGICAL SYNAPSE: A MODEL FOR SECRETORY LYSOSOME FUNCTION}

Lyst and the adaptor complexes play important roles in lysosome biogenesis as described above, as well as in the biogenesis of secretory lysosomes and LROs. However, the next few proteins that emerged as critical for CTL secretion appear to be specialized for secretory lysosomes and LROs alone. Figure 4 summarizes the functions of these proteins in the final steps of secretion at the immunological synapse formed 


\section{J.P. Luzio et al.}

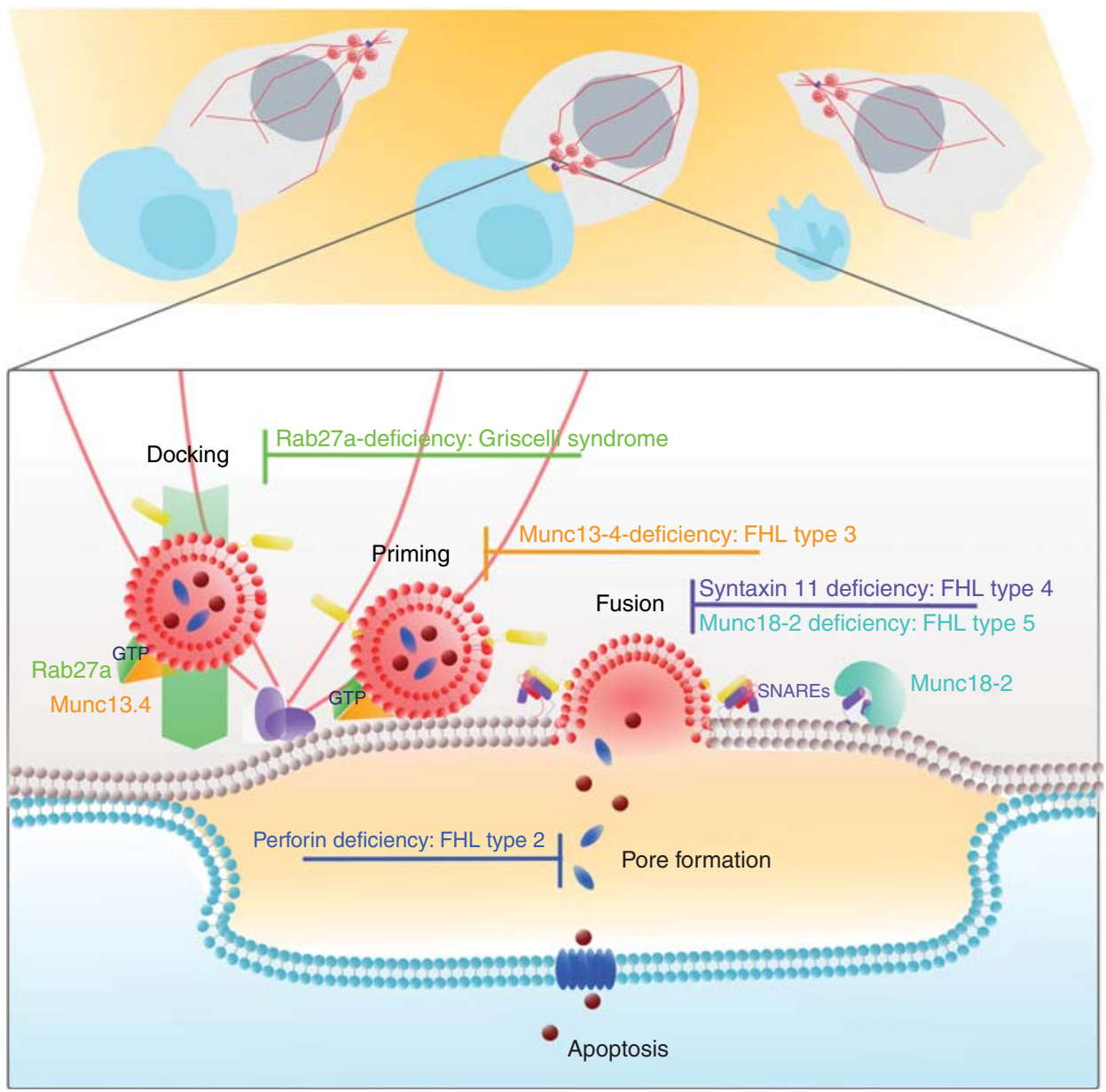

Figure 4. Genetic diseases giving rise to familial hemophagocytic lymphohistiocytosis (FHL). (Top panel) When CTLs (gray) encounter a target (blue), the centrosome (purple) polarizes and docks at the immunological synapse formed with the target. Secretory lysosomes (red circles) move along microtubules (red lines) and are focused at the point of centrosome docking. (Lower panel) At the immunological synapse, secretory lysosomes dock, prime, and undergo fusion at the plasma membrane into a small secretory cleft, and perforin (blue) forms a pore in the target cell allowing entry of granzymes (brown), which trigger apoptosis. Loss of perforin leads to FHL2. Rab27a and Munc13-4 associate with granules and are required for docking and priming, respectively. Syntaxin 11 and Munc18-2 are thought to be required for fusion by assisting formation of the final SNARE complex.

between CTLs and the target cells that they destroy by the focal release of perforin and granzymes. CTLs and NK cells are important cells of the immune system, recognizing and destroying virally infected and tumor cells. Because their killing is so potent, it is important that killing is focused at the precise site of recognition between killer and target. This is accomplished by polarization of the centrosome to the plas- ma membrane at the point of contact (known as the immunological synapse). Once CTLs and NKs recognize their targets, the secretory lysosomes move along microtubules toward the synapse, then dock and deliver their contents toward the target cell. Immunodeficiencies giving rise to the four known types of familial hemophagocytic lymphohistiocytosis (FHL) and one giving rise to Griscelli syndrome, which 
combines FHL with albinism, have identified four important proteins that are critical in these final steps of secretion (Fig. 4).

\section{Rab27A: THE TURNSTILE BETWEEN DOCKING AND SECRETION}

Rab27A belongs to the family of small GTPases that function as molecular switches in different membrane transport processes (Hutagalung and Novick 2011; Park 2013). Rab27a is a key player in the release of secretory lysosomes not only from CTLs (Kornfeld and Mellman 1989; Haddad et al. 2001; Stinchcombe et al. 2001), but also from neutrophils (Brzezinska et al. 2008; Herrero-Turrion et al. 2008), endothelial cells (Nightingale et al. 2009; Rojo Pulido et al. 2011), melanocytes (Hume et al. 2001; Wu et al. 2001), and platelets (Shirakawa et al. 2004). Loss of functional Rab27A protein causes Griscelli syndrome type 2 (GS2), characterized by partial albinism and immunodeficiency. Lytic granules in CTL from GS2 patients polarize normally to the immunological synapse but seem to remain attached to the microtubules, resembling beads on a string (Stinchcombe et al. 2004), suggesting that Rab27a facilitates granule detachment and docking. The function of Rab27a in lysosome secretion is linked to other effectors it binds to in other cell types (Fukuda 2013). Whereas active Rab27A binds directly to Munc13-4 and synaptotagmin-like proteins in CTLs, NK cells, and platelets, Rab27a binds melanophilin in melanocytes, providing a link to myosin $\mathrm{V}$ for docking. By binding different effector proteins, Rab27a can be seen as a turnstile, controlling its precise mode of action according to the partner bound. In this way, Rab27a regulates different modes of secretory lysosome release in different cell types.

\section{REGULATION OF THE FINAL STAGES OF SECRETION}

The function of Rab27a during CTL and NK cell lytic granule release is linked to Munc13-4, which is thought to regulate the priming for secretion. Mutations in Munc13-4 cause FHL type 3 characterized by secretory granules that dock but fail to fuse with the plasma membrane (Feldmann et al. 2003). Data showing a direct interaction between Rab27A and Munc13-4 further support the model in which Rab27a and Munc13-4 bridge lytic granule docking and priming (Shirakawa et al. 2005).

Munc13-4 is also critical for secretion of lysosomes from neutrophils and NK cells in which Munc13-4 was shown to arrest the movement of Rab27a-positive vesicles at the site of secretion (Elstak et al. 2011; Johnson et al. 2011). This tethering function is most likely exerted by the central MUN domain, resembling vesicle-tethering proteins such as Sec6p (Pei et al. 2009; Li et al. 2011), thus potentially engaging with membranes directly or via other tethering factors (Guan et al. 2008). Additionally, two C2 domains, framing the central MUN domain, could also play a role in tethering of secretory lysosomes and LROs at the target membrane by binding phospholipid head groups or t-SNARE complexes present on the target membrane. Moreover, reports propose an interaction between the MUN domain and syntaxin 11, which may initiate SNARE complex formation (Boswell et al. 2012).

The final steps of lysosomal secretion are facilitated by SNARE proteins and accessory proteins that control SNARE activity (Rizo and Sudhof 2012). In 2005, syntaxin 11 (Stx11)deficient patients, classified as FHL4, showed reduced CTL and NK cell effector function and impaired platelet dense granule secretion (zur Stadt et al. 2005; Rudd et al. 2006). Understanding the exact function of Stx 11 during lytic granule release from CTLs and NK cells is complicated by the fact that different studies show different cellular distributions for Stx11 (Advani et al. 1998; Valdez et al. 1999; Prekeris et al. 2000; Arneson et al. 2007; Zhang et al. 2008). Stx11 was shown to form a SNARE complex with SNAP23 and VAMP3/8 (Ye et al. 2012), suggesting an active role of Stx11 during membrane fusion events, although other studies suggested an inhibitory, SNARE protein-sequestering function (Grote et al. 2000). Whether that is during fusion of secretory lysosomes at the plasma membrane or potentially earlier during secretory lysosome maturation as suggested pre- 
viously in CTLs (Dabrazhynetskaya et al. 2012) remains to be determined.

In 2009, another genetic locus associated with primary immunodeficiency, which encodes the syntaxin-binding protein Munc18-2 (FHL5), was described (Cote et al. 2009; zur Stadt et al. 2009). Loss of Munc18-2 not only affects secretion from CTLs and NK cells, but also from mast cells (Bin et al. 2013), platelets (Al Hawas et al. 2012), and neutrophils (Zhao et al. 2013). Strikingly, NK cell and CTL degranulation in FHL5 patients is often restored upon culture with IL2, similar to FHL4 patients (Cote et al. 2009; zur Stadt et al. 2009; Pagel et al. 2012). This link fits with the finding that Munc18-2 binds Stx11 and potentially acts as its chaperone, as judged by a reduced Stx11 protein level in FHL5 patient cells (Cote et al. 2009; zur Stadt et al. 2009; Cetica et al. 2010). Because polarization and docking of lytic granules in CTLs from FHL5 patients seem normal, it appears that Munc18-2 functions late during secretion, similar to its neuronal homolog Munc18-1. However, to date, little is known about the interaction between Stx11 and Munc18-2 and whether it functions in a similar fashion to the neuronal homologs.

\section{CONCLUDING REMARKS AND FUTURE PERSPECTIVES}

The biosynthesis of lysosomes requires multiple trafficking routes out of the TGN for newly synthesized lysosomal proteins that deliver directly or indirectly to endosomes. The evidence to date is consistent with the generation of lysosomes occurring as a result of re-formation or budding from endolysosomes/autolysosomes that have been formed from fusions of preexisting lysosomes and late endosomes/autophagosomes. New roles for the lysosome make clear that it is not simply the end point for endocytosis. Recent discoveries show that the lysosome is an organelle important in nutrient sensing, signaling to the nucleus and many different forms of specialized secretion. These diverse functions put the lysosome center stage, and just how these many functions are coordinated becomes an intriguing question for the future.
There remain many challenges to achieving a full understanding of lysosome biogenesis. We need better ways to distinguish endolysosomes from lysosomes and to characterize the steps and processes occurring in the maturation of endolysosomes to lysosomes. The complexity of fusion events in the late endocytic and autophagic pathways requires a far better knowledge of the SNARE complexes involved and their regulation. In addition, we are woefully ignorant of the machinery of fission events that would enable several lysosomes to be generated from one endolysosome and/or allow these organelles to divide.

Although many of the important proteins required for lysosomal secretion have been identified, the series of events leading to secretion and the precise series of molecular interactions involving these proteins are not yet understood. There are very likely additional components yet to be identified, and, from the data available now, it seems likely that these will vary from one cell type to another. Rab27a illustrates this concept beautifully, interacting with melanophilin in melanocytes and with Munc13-4 in CTLs to facilitate secretion of different lysosome-related organelles. It is clear that there are many variations on a theme that operate in different cell types, providing optimal mechanisms for lysosomal secretion in each cell type.

The advent of new microscopy techniques for following lysosomal biogenesis in real time and the ability to perturb individual proteins will undoubtedly bring new insights in this area. With the increased ability to study specialized cell types, a more complete understanding of lysosome biogenesis and secretion should emerge.

\section{ACKNOWLEDGMENTS}

J.P.L. is supported by MRC programme grant G0900113; G.M.G. by Wellcome Trust Principal Research Fellowship 075880; N.M.G.D. by Wellcome Trust 4-year PhD programme (097024); and Y.H. by the NIHR BRC. The Cambridge Institute for Medical Research is supported by a Wellcome Trust Strategic Award (100140). 


\section{REFERENCES}

${ }^{*}$ Reference is also in this collection.

Advani RJ, Bae HR, Bock JB, Chao DS, Doung YC, Prekeris R, Yoo JS, Scheller RH. 1998. Seven novel mammalian SNARE proteins localize to distinct membrane compartments. J Biol Chem 273: 10317-10324.

Al Hawas R, Ren Q, Ye S, Karim ZA, Filipovich AH, Whiteheart SW. 2012. Munc18b/STXBP2 is required for platelet secretion. Blood 120: 2493-2500.

Andrews NW. 2002. Lysosomes and the plasma membrane: Trypanosomes reveal a secret relationship. J Cell Biol 158: 389-394.

Antonin W, Holroyd C, Fasshauer D, Pabst S, Von Mollard GF, Jahn R. 2000. A SNARE complex mediating fusion of late endosomes defines conserved properties of SNARE structure and function. EMBO J 19: 6453-6464.

Arneson LN, Brickshawana A, Segovis CM, Schoon RA, Dick CJ, Leibson PJ. 2007. Cutting edge: Syntaxin 11 regulates lymphocyte-mediated secretion and cytotoxicity. J Immunol 179: 3397-3401.

Attar N, Cullen PJ. 2010. The retromer complex. Adv Enzyme Regul 50: 216-236.

Baetz K, Isaaz S, Griffiths GM. 1995. Loss of cytotoxic T lymphocyte function in Chédiak-Higashi syndrome arises from a secretory defect that prevents lytic granule exocytosis. J Immunol 154: 6122-6131.

Bainton DF. 1981. The discovery of lysosomes. J Cell Biol 91: $66 \mathrm{~s}-76 \mathrm{~s}$

Balderhaar HJ, Ungermann C. 2013. CORVET and HOPS tethering complexes-Coordinators of endosome and lysosome fusion. J Cell Sci 126: 1307-1316.

Baran K, Dunstone M, Chia J, Ciccone A, Browne KA, Clarke CJ, Lukoyanova N, Saibil H, Whisstock JC, Voskoboinik I, et al. 2009. The molecular basis for perforin oligomerization and transmembrane pore assembly. Immunity 30: 684-695.

Baum W, Kirkin V, Fernandez SB, Pick R, Lettau M, Janssen O, Zornig M. 2005. Binding of the intracellular Fas ligand (FasL) domain to the adaptor protein PSTPIP results in a cytoplasmic localization of FasL. J Biol Chem 280: 40012-40024

Bin NR, Jung CH, Piggott C, Sugita S. 2013. Crucial role of the hydrophobic pocket region of Munc18 protein in mast cell degranulation. Proc Natl Acad Sci 110: 46104615.

Blott EJ, Bossi G, Clark R, Zvelebil M, Griffiths GM. 2001. Fas ligand is targeted to secretory lysosomes via a prolinerich domain in its cytoplasmic tail. J Cell Sci 114: 24052416.

Bossi G, Griffiths GM. 1999. Degranulation plays an essential part in regulating cell surface expression of Fas ligand in T cells and natural killer cells. Nat Med 5: 90-96.

Boswell KL, James DJ, Esquibel JM, Bruinsma S, Shirakawa R, Horiuchi H, Martin TF. 2012. Munc13-4 reconstitutes calcium-dependent SNARE-mediated membrane fusion. J Cell Biol 197: 301-312.

Braulke T, Bonifacino JS. 2009. Sorting of lysosomal proteins. Biochim Biophys Acta 1793: 605-614.
Braun V, Fraisier V, Raposo G, Hurbain I, Sibarita JB Chavrier P, Galli T, Niedergang F. 2004. TI-VAMP/ VAMP7 is required for optimal phagocytosis of opsonised particles in macrophages. EMBO J 23: 4166-4176.

Brennan AJ, Chia J, Browne KA, Ciccone A, Ellis S, Lopez JA, Susanto O, Verschoor S, Yagita H, Whisstock JC, et al. 2011. Protection from endogenous perforin: Glycans and the $\mathrm{C}$ terminus regulate exocytic trafficking in cytotoxic lymphocytes. Immunity 34: 879-892.

Bright NA, Reaves BJ, Mullock BM, Luzio JP. 1997. Dense core lysosomes can fuse with late endosomes and are reformed from the resultant hybrid organelles. J Cell Sci 110: 2027-2040.

Bright NA, Gratian MJ, Luzio JP. 2005. Endocytic delivery to lysosomes mediated by concurrent fusion and kissing events in living cells. Curr Biol 15: 360-365.

Brown WJ, Goodhouse J, Farquhar MG. 1986. Mannose6-phosphate receptors for lysosomal enzymes cycle between the Golgi complex and endosomes. J Cell Biol 103: 1235-1247.

Brzezinska AA, Johnson JL, Munafo DB, Crozat K, Beutler B, Kiosses WB, Ellis BA, Catz SD. 2008. The Rab27a effectors JFC1/Slp1 and Munc13-4 regulate exocytosis of neutrophil granules. Traffic 9: 2151-2164.

Burkhardt JK, Hester S, Argon Y. 1989. Two proteins targeted to the same lytic granule compartment undergo very different posttranslational processing. Proc Natl Acad Sci 86: $7128-7132$.

Cetica V, Santoro A, Gilmour KC, Sieni E, Beutel K, Pende D, Marcenaro S, Koch F, Grieve S, Wheeler R, et al. 2010. STXBP2 mutations in children with familial haemophagocytic lymphohistiocytosis type 5. J Med Genet 47: 595600.

Clark RH, Stinchcombe JC, Day A, Blott E, Booth S, Bossi G, Hamblin T, Davies EG, Griffiths GM. 2003. Adaptor protein 3-dependent microtubule-mediated movement of lytic granules to the immunological synapse. Nat Immunol 4: 1111-1120.

Cote M, Menager MM, Burgess A, Mahlaoui N, Picard C, Schaffner C, Al-Manjomi F, Al-Harbi M, Alangari A, Le Deist F, et al. 2009. Munc18-2 deficiency causes familial hemophagocytic lymphohistiocytosis type 5 and impairs cytotoxic granule exocytosis in patient NK cells. J Clin Invest 119: 3765-3773.

Coutinho MF, Prata MJ, Alves S. 2012. A shortcut to the lysosome: The mannose-6-phosphate-independent pathway. Mol Genet Metab 107: 257-266.

Dabrazhynetskaya A, Ma J, Guerreiro-Cacais AO, Arany Z, Rudd E, Henter JI, Karre K, Levitskaya J, Levitsky V. 2012. Syntaxin 11 marks a distinct intracellular compartment recruited to the immunological synapse of NK cells to colocalize with cytotoxic granules. J Cell Mol Med 16: $129-141$.

Danglot L, Zylbersztejn K, Petkovic M, Gauberti M, Meziane $\mathrm{H}$, Combe R, Champy MF, Birling MC, Pavlovic G, Bizot JC, et al. 2012. Absence of TI-VAMP/Vamp7 leads to increased anxiety in mice. J Neurosci 32: 19621968.

de Duve C. 2005. The lysosome turns fifty. Nat Cell Biol 7: $847-849$.

Divangahi M, Chen M, Gan H, Desjardins D, Hickman TT, Lee DM, Fortune S, Behar SM, Remold HG. 2009. 
J.P. Luzio et al.

Mycobacterium tuberculosis evades macrophage defenses by inhibiting plasma membrane repair. Nat Immunol 10: 899-906.

Doyle EL, Ridger V, Ferraro F, Turmaine M, Saftig P, Cutler DF. 2011. CD63 is an essential cofactor to leukocyte recruitment by endothelial P-selectin. Blood 118: 42654273.

Durchfort N, Verhoef S, Vaughn MB, Shrestha R, Adam D, Kaplan J, Ward DM. 2012. The enlarged lysosomes in beige $_{j}$ cells result from decreased lysosome fission and not increased lysosome fusion. Traffic 13: 108-119.

Elstak ED, Neeft M, Nehme NT, Voortman J, Cheung M, Goodarzifard M, Gerritsen HC, van Bergen En Henegouwen PM, Callebaut I, de Saint Basile G, et al. 2011. The munc13-4-rab27 complex is specifically required for tethering secretory lysosomes at the plasma membrane. Blood 118: 1570-1578.

Fader CM, Sanchez DG, Mestre MB, Colombo MI. 2009. TI-VAMP/VAMP7 and VAMP3/cellubrevin: Two vSNARE proteins involved in specific steps of the autophagy/multivesicular body pathways. Biochim Biophys Acta 1793: 1901-1916.

Feldmann J, Callebaut I, Raposo G, Certain S, Bacq D, Dumont C, Lambert N, Ouachee-Chardin M, Chedeville G, Tamary H, et al. 2003. Munc13-4 is essential for cytolytic granules fusion and is mutated in a form of familial hemophagocytic lymphohistiocytosis (FHL3). Cell 115: 461-473.

Fraldi A, Annunziata F, Lombardi A, Kaiser HJ, Medina DL, Spampanato C, Fedele AO, Polishchuk R, Sorrentino NC, Simons K, et al. 2010. Lysosomal fusion and SNARE function are impaired by cholesterol accumulation in lysosomal storage disorders. EMBO J 29: 3607-3620.

Fukuda M. 2013. Rab27 effectors, pleiotropic regulators in secretory pathways. Traffic 14: 949-963.

Futter CE, Pearse A, Hewlett LJ, Hopkins CR. 1996. Multivesicular endosomes containing internalized EGF-EGF receptor complexes mature and then fuse directly with lysosomes. J Cell Biol 132: 1011-1023.

Gan Z, Ram S, Vaccaro C, Ober RJ, Ward ES. 2009. Analyses of the recycling receptor, FcRn, in live cells reveal novel pathways for lysosomal delivery. Traffic 10: 600-614.

Ghosh P, Dahms NM, Kornfeld S. 2003. Mannose 6-phosphate receptors: New twists in the tale. Nat Rev Mol Cell Biol 4: 202-212.

Griffiths GM, Isaaz S. 1993. Granzymes A and B are targeted to the lytic granules of lymphocytes by the mannose6-phosphate receptor. J Cell Biol 120: 885-896.

Griffiths G, Hoflack B, Simons K, Mellman I, Kornfeld S. 1988. The mannose 6-phosphate receptor and the biogenesis of lysosomes. Cell 52: 329-341.

Grote E, Baba M, Ohsumi Y, Novick PJ. 2000. Geranylgeranylated SNAREs are dominant inhibitors of membrane fusion. J Cell Biol 151: 453-466.

Guan R, Dai H, Rizo J. 2008. Binding of the Munc13-1 MUN domain to membrane-anchored SNARE complexes. Biochemistry 47: 1474-1481.

Haddad EK, Wu X, Hammer JA 3rd, Henkart PA. 2001. Defective granule exocytosis in Rab27a-deficient lymphocytes from Ashen mice. J Cell Biol 152: 835-842.
Harrison-Lavoie KJ, Michaux G, Hewlett L, Kaur J, Hannah MJ, Lui-Roberts WW, Norman KE, Cutler DF. 2006. P-selectin and CD63 use different mechanisms for delivery to Weibel-Palade bodies. Traffic 7: 647-662.

Henkart PA, Millard PJ, Reynolds CW, Henkart MP. 1984. Cytolytic activity of purified cytoplasmic granules from cytotoxic rat large granular lymphocyte tumors. J Exp Med 160: 75-93.

Henkart PA, Yue CC, Yang J, Rosenberg SA. 1986. Cytolytic and biochemical properties of cytoplasmic granules of murine lymphokine-activated killer cells. J Immunol 137: 2611-2617.

Hermansky F, Pudlak P. 1959. Albinism associated with hemorrhagic diathesis and unusual pigmented reticular cells in the bone marrow: Report of two cases with histochemical studies. Blood 14: 162-169.

Herrero-Turrion MJ, Calafat J, Janssen H, Fukuda M, Mollinedo F. 2008. Rab27a regulates exocytosis of tertiary and specific granules in human neutrophils. J Immunol 181: 3793-3803.

Hirota Y, Masuyama N, Kuronita T, Fujita H, Himeno M, Tanaka Y. 2004. Analysis of post-lysosomal compartments. Biochem Biophys Res Commun 314: 306-312.

Hirst J, Futter CE, Hopkins CR. 1998. The kinetics of mannose 6-phosphate receptor trafficking in the endocytic pathway in HEp-2 cells: The receptor enters and rapidly leaves multivesicular endosomes without accumulating in a prelysosomal compartment. Mol Biol Cell 9: 809816.

Huizing M, Scher CD, Strovel E, Fitzpatrick DL, Hartnell LM, Anikster Y, Gahl WA. 2002. Nonsense mutations in $A D T B 3 A$ cause complete deficiency of the $\beta 3$ A subunit of adaptor complex-3 and severe Hermansky-Pudlak syndrome type 2. Pediatr Res 51: 150-158.

Hume AN, Collinson LM, Rapak A, Gomes AQ, Hopkins CR, Seabra MC. 2001. Rab27a regulates the peripheral distribution of melanosomes in melanocytes. J Cell Biol 152: 795-808.

Huotari J, Helenius A. 2011. Endosome maturation. EMBO J 30: 3481-3500.

Hutagalung AH, Novick PJ. 2011. Role of Rab GTPases in membrane traffic and cell physiology. Phys Rev 91: $119-149$.

Jahreiss L, Menzies FM, Rubinsztein DC. 2008. The itinerary of autophagosomes: From peripheral formation to kissand-run fusion with lysosomes. Traffic 9: 574-587.

Jaiswal JK, Andrews NW, Simon SM. 2002. Membrane proximal lysosomes are the major vesicles responsible for calcium-dependent exocytosis in nonsecretory cells. J Cell Biol 159: 625-635.

Johnson JL, Hong H, Monfregola J, Kiosses WB, Catz SD. 2011. Munc13-4 restricts motility of Rab27a-expressing vesicles to facilitate lipopolysaccharide-induced priming of exocytosis in neutrophils. J Biol Chem 286: 56475656.

Kent HM, Evans PR, Schafer IB, Gray SR, Sanderson CM, Luzio JP, Peden AA, Owen DJ. 2012. Structural basis of the intracellular sorting of the SNARE VAMP7 by the AP3 adaptor complex. Dev Cell 22: 979-988. 
* Klumperman J, Raposo G. 2014. The complex ultrastructure of the endolysosomal system. Cold Spring Harb Perspect Biol doi: 10.1101/cshperspect.a016857.

Kojima Y, Kawasaki-Koyanagi A, Sueyoshi N, Kanai A, Yagita H, Okumura K. 2002. Localization of Fas ligand in cytoplasmic granules of $\mathrm{CD}^{+}$cytotoxic T lymphocytes and natural killer cells: Participation of Fas ligand in granule exocytosis model of cytotoxicity. Biochem Biophys Res Commun 296: 328-336.

Kornfeld S, Mellman I. 1989. The biogenesis of lysosomes. Annu Rev Cell Biol 5: 483-525.

Krzewski K, Gil-Krzewska A, Nguyen V, Peruzzi G, Coligan JE. 2013. LAMP1/CD107a is required for efficient perforin delivery to lytic granules and NK-cell cytotoxicity. Blood 121: 4672-4683

Laulagnier K, Schieber NL, Maritzen T, Haucke V, Parton RG, Gruenberg J. 2011. Role of AP1 and Gadkin in the traffic of secretory endo-lysosomes. Mol Biol Cell 22: 2068-2082.

Law RH, Lukoyanova N, Voskoboinik I, Caradoc-Davies TT, Baran K, Dunstone MA, D'Angelo ME, Orlova EV, Coulibaly F, Verschoor S, et al. 2010. The structural basis for membrane binding and pore formation by lymphocyte perforin. Nature 468: 447-451.

Li D, Ropert N, Koulakoff A, Giaume C, Oheim M. 2008. Lysosomes are the major vesicular compartment undergoing $\mathrm{Ca}^{2+}$-regulated exocytosis from cortical astrocytes. J Neurosci 28: 7648-7658.

Li W, Ma C, Guan R, Xu Y, Tomchick DR, Rizo J. 2011. The crystal structure of a Munc13 C-terminal module exhibits a remarkable similarity to vesicle tethering factors. Structure 19: 1443-1455.

Lloyd-Evans E, Morgan AJ, He X, Smith DA, Elliot-Smith E, Sillence DJ, Churchill GC, Schuchman EH, Galione A, Platt FM. 2008. Niemann-Pick disease type C1 is a sphingosine storage disease that causes deregulation of lysosomal calcium. Nat Med 14: 1247-1255.

Lowrey DM, Aebischer T, Olsen K, Lichtenheld M, Rupp F, Hengartner H, Podack ER. 1989. Cloning, analysis, and expression of murine perforin $1 \mathrm{cDNA}$, a component of cytolytic T-cell granules with homology to complement component C9. Proc Natl Acad Sci 86: 247-251.

Lui-Roberts WW, Collinson LM, Hewlett LJ, Michaux G, Cutler DF. 2005. An AP1/clathrin coat plays a novel and essential role in forming the Weibel-Palade bodies of endothelial cells. J Cell Biol 170: 627-636.

Luzio JP, Pryor PR, Bright NA. 2007. Lysosomes: Fusion and function. Nat Rev Mol Cell Biol 8: 622-632.

Marks MS, Heijnen HF, Raposo G. 2013. Lysosome-related organelles: Unusual compartments become mainstream. Curr Opin Cell Biol 25: 495-505.

Medina DL, Fraldi A, Bouche V, Annunziata F, Mansueto G, Spampanato C, Puri C, Pignata A, Martina JA, Sardiello M, et al. 2011. Transcriptional activation of lysosomal exocytosis promotes cellular clearance. Dev Cell 21: 421-430.

Miller SE, Sahlender DA, Graham SC, Honing S, Robinson MS, Peden AA, Owen DJ. 2011. The molecular basis for the endocytosis of small R-SNAREs by the clathrin adaptor CALM. Cell 147: 1118-1131.
Mullock BM, Perez JH, Kuwana T, Gray SR, Luzio JP. 1994. Lysosomes can fuse with a late endosomal compartment in a cell-free system from rat liver. J Cell Biol 126: $1173-$ 1182.

Mullock BM, Bright NA, Fearon CW, Gray SR, Luzio JP. 1998. Fusion of lysosomes with late endosomes produces a hybrid organelle of intermediate density and is NSF dependent. J Cell Biol 140: 591-601.

Nightingale TD, Pattni K, Hume AN, Seabra MC, Cutler DF 2009. Rab27a and MyRIP regulate the amount and multimeric state of VWF released from endothelial cells. Blood 113: $5010-5018$.

Pagel J, Beutel K, Lehmberg K, Koch F, Maul-Pavicic A, Rohlfs AK, Al-Jefri A, Beier R, Bomme Ousager L, Ehlert $\mathrm{K}$, et al. 2012. Distinct mutations in STXBP2 are associated with variable clinical presentations in patients with familial hemophagocytic lymphohistiocytosis type 5 (FHL5). Blood 119: 6016-6024.

Park HH. 2013. Structural basis of membrane trafficking by Rab family small G protein. Int J Mol Sci 14: $8912-$ 8923.

Pei J, Ma C, Rizo J, Grishin NV. 2009. Remote homology between Munc13 MUN domain and vesicle tethering complexes. J Mol Biol 391: 509-517.

Platt FM, Boland B, van der Spoel AC. 2012. The cell biology of disease: Lysosomal storage disorders: The cellular impact of lysosomal dysfunction. J Cell Biol 199: $723-734$.

Podack ER, Young JD, Cohn ZA. 1985. Isolation and biochemical and functional characterization of perforin 1 from cytolytic T-cell granules. Proc Natl Acad Sci 82: 8629-8633.

Pols MS, ten Brink C, Gosavi P, Oorschot V, Klumperman J. 2013a. The HOPS proteins hVps41 and hVps39 are required for homotypic and heterotypic late endosome fusion. Traffic 14: 219-232.

Pols MS, van Meel E, Oorschot V, ten Brink C, Fukuda M, Swetha MG, Mayor S, Klumperman J. 2013b. hVps41 and VAMP7 function in direct TGN to late endosome transport of lysosomal membrane proteins. Nat Commun 4: 1361.

Prekeris R, Klumperman J, Scheller RH. 2000. Syntaxin 11 is an atypical SNARE abundant in the immune system. Eur J Cell Biol 79: 771-780.

Pryor PR, Mullock BM, Bright NA, Gray SR, Luzio JP. 2000. The role of intraorganellar $\mathrm{Ca}^{2+}$ in late endosomelysosome heterotypic fusion and in the reformation of lysosomes from hybrid organelles. J Cell Biol 149: 10531062.

Pryor PR, Mullock BM, Bright NA, Lindsay MR, Gray SR, Richardson SC, Stewart A, James DE, Piper RC, Luzio JP. 2004. Combinatorial SNARE complexes with VAMP7 or VAMP8 define different late endocytic fusion events. EMBO Rep 5: 590-595.

Rao SK, Huynh C, Proux-Gillardeaux V, Galli T, Andrews NW. 2004. Identification of SNAREs involved in synaptotagmin VII-regulated lysosomal exocytosis. J Biol Chem 279: 20471-20479.

Raposo G, Marks MS, Cutler DF. 2007. Lysosome-related organelles: Driving post-Golgi compartments into specialisation. Curr Opin Cell Biol 19: 394-401. 
J.P. Luzio et al.

Reddy A, Caler EV, Andrews NW. 2001. Plasma membrane repair is mediated by $\mathrm{Ca}^{2+}$-regulated exocytosis of lysosomes. Cell 106: 157-169.

Rizo J, Sudhof TC. 2012. The membrane fusion enigma: SNAREs, Sec1/Munc18 proteins, and their accomplices-Guilty as charged? Ann Rev Cell Dev Biol 28: 279308.

Rojo Pulido I, Nightingale TD, Darchen F, Seabra MC, Cutler DF, Gerke V. 2011. Myosin Va acts in concert with Rab27a and MyRIP to regulate acute von-Willebrand factor release from endothelial cells. Traffic 12: 1371-1382.

Rudd E, Goransdotter Ericson K, Zheng C, Uysal Z, Ozkan A, Gurgey A, Fadeel B, Nordenskjold M, Henter JI 2006. Spectrum and clinical implications of syntaxin 11 gene mutations in familial haemophagocytic lymphohistiocytosis: Association with disease-free remissions and haematopoietic malignancies. J Med Genet 43: e14.

Saftig P, Klumperman J. 2009. Lysosome biogenesis and lysosomal membrane proteins: Trafficking meets function. Nat Rev Mol Cell Biol 10: 623-635.

Sardiello M, Palmieri M, di Ronza A, Medina DL, Valenza M, Gennarino VA, Di Malta C, Donaudy F, Embrione V, Polishchuk RS, et al. 2009. A gene network regulating lysosomal biogenesis and function. Science 325: 473477.

Sato M, Yoshimura S, Hirai R, Goto A, Kunii M, Atik N, Sato T, Sato K, Harada R, Shimada J, et al. 2011. The role of VAMP7/TI-VAMP in cell polarity and lysosomal exocytosis in vivo. Traffic 12: 1383-1393.

Schmid JA, Mach L, Paschke E, Glossl J. 1999. Accumulation of sialic acid in endocytic compartments interferes with the formation of mature lysosomes. Impaired proteolytic processing of cathepsin B in fibroblasts of patients with lysosomal sialic acid storage disease. J Biol Chem 274: 19063-19071.

Schwake M, Schroder B, Saftig P. 2013. Lysosomal membrane proteins and their central role in physiology. Traffic 14: $739-748$.

* Settembre C, Ballabio A. 2014. Lysosomal adaptation: How the lysosome responds to external cues. Cold Spring Harb Perspect Biol doi: 10.1101/cshperspect.a016907.

Settembre C, Fraldi A, Medina DL, Ballabio A. 2013. Signals from the lysosome: A control centre for cellular clearance and energy metabolism. Nat Rev Mol Cell Biol 14: 283296.

Shirakawa R, Higashi T, Tabuchi A, Yoshioka A, Nishioka H, Fukuda M, Kita T, Horiuchi H. 2004. Munc13-4 is a GTPRab27-binding protein regulating dense core granule secretion in platelets. J Biol Chem 279: 10730-10737.

Shirakawa R, Higashi T, Kondo H, Yoshioka A, Kita T, Horiuchi H. 2005. Purification and functional analysis of a Rab27 effector Munc 13-4 using a semi-intact platelet dense-granule secretion assay. Methods Enzymol 403: $778-788$.

Sitaram A, Marks MS. 2012. Mechanisms of protein delivery to melanosomes in pigment cells. Physiology 27: 85-99.

Spampanato C, Feeney E, Li L, Cardone M, Lim JA, Annunziata F, Zare H, Polishchuk R, Puertollano R, Parenti G, et al. 2013. Transcription factor EB (TFEB) is a new thera- peutic target for Pompe disease. EMBO Mol Med 5: 691706.

Stinchcombe JC, Barral DC, Mules EH, Booth S, Hume AN, Machesky LM, Seabra MC, Griffiths GM. 2001. Rab27a is required for regulated secretion in cytotoxic T lymphocytes. J Cell Biol 152: 825-834.

Stinchcombe J, Bossi G, Griffiths GM. 2004. Linking albinism and immunity: The secrets of secretory lysosomes. Science 305: 55-59.

Theos AC, Tenza D, Martina JA, Hurbain I, Peden AA, Sviderskaya EV, Stewart A, Robinson MS, Bennett DC, Cutler DF, et al. 2005. Functions of adaptor protein (AP)3 and AP1 in tyrosinase sorting from endosomes to melanosomes. Mol Biol Cell 16: 5356-5372.

Thornhill PB, Cohn JB, Drury G, Stanford WL, Bernstein A, Desbarats J. 2007. A proteomic screen reveals novel Fas ligand interacting proteins within nervous system Schwann cells. FEBS Lett 581: 4455-4462.

Treusch S, Knuth S, Slaugenhaupt SA, Goldin E, Grant BD, Fares H. 2004. Caenorhabditis elegans functional orthologue of human protein h-mucolipin-1 is required for lysosome biogenesis. Proc Natl Acad Sci 101: 4483-4488.

Tribl F, Marcus K, Meyer HE, Bringmann G, Gerlach M, Riederer P. 2006. Subcellular proteomics reveals neuromelanin granules to be a lysosome-related organelle. $J$ Neural Transmission 113: 741-749.

Uellner R, Zvelebil MJ, Hopkins J, Jones J, MacDougall LK, Morgan BP, Podack E, Waterfield MD, Griffiths GM. 1997. Perforin is activated by a proteolytic cleavage during biosynthesis which reveals a phospholipid-binding C2 domain. EMBO J 16: 7287-7296.

Valdez AC, Cabaniols JP, Brown MJ, Roche PA. 1999. Syntaxin 11 is associated with SNAP23 on late endosomes and the trans-Golgi network. J Cell Sci 112: 845-854.

Vanlandingham PA, Ceresa BP. 2009. Rab7 regulates late endocytic trafficking downstream of multivesicular body biogenesis and cargo sequestration. J Biol Chem 284: $12110-12124$.

Ward DM, Griffiths GM, Stinchcombe JC, Kaplan J. 2000a. Analysis of the lysosomal storage disease Chédiak-Higashi syndrome. Traffic 1: 816-822.

Ward DM, Pevsner J, Scullion MA, Vaughn M, Kaplan J. 2000b. Syntaxin 7 and VAMP-7 are soluble $N$-ethylmaleimide-sensitive factor attachment protein receptors required for late endosome-lysosome and homotypic lysosome fusion in alveolar macrophages. Mol Biol Cell 11: $2327-2333$.

Weaver T, Na C, Stahlman M. 2002. Biogenesis of lamellar bodies, lysosome-related organelles involved in storage and secretion of pulmonary syrfactant. Cell Dev Biol 13: 263-270.

Wenham M, Grieve S, Cummins M, Jones ML, Booth S, Kilner R, Ancliff PJ, Griffiths GM, Mumford AD. 2010. Two patients with Hermansky Pudlak syndrome type 2 and novel mutations in AP3B1. Haematologica 95: $333-$ 337.

Woodman PG, Futter CE. 2008. Multivesicular bodies: Co-ordinated progression to maturity. Curr Opin Cell Biol 20: 408-414.

Wu X, Rao K, Bowers MB, Copeland NG, Jenkins NA, Hammer JA 3rd. 2001. Rab27a enables myosin Va-dependent 
Lysosome Biogenesis

melanosome capture by recruiting the myosin to the organelle. J Cell Sci 114: 1091-1100.

Ye S, Karim ZA, Al Hawas R, Pessin JE, Filipovich AH, Whiteheart SW. 2012. Syntaxin-11, but not syntaxin-2 or syntaxin-4, is required for platelet secretion. Blood 120: $2484-2492$

Yu L, McPhee CK, Zheng L, Mardones GA, Rong Y, Peng J, Mi N, Zhao Y, Liu Z, Wan F, et al. 2010. Termination of autophagy and reformation of lysosomes regulated by mTOR. Nature 465: 942-946.

Zhang Z, Chen G, Zhou W, Song A, Xu T, Luo Q, Wang W, Gu XS, Duan S. 2007. Regulated ATP release from astrocytes through lysosome exocytosis. Nat Cell Biol 9: 945-953.

Zhang S, Ma D, Wang X, Celkan T, Nordenskjold M, Henter JI, Fadeel B, Zheng C. 2008. Syntaxin-11 is expressed in primary human monocytes/macrophages and acts as a negative regulator of macrophage engulfment of apoptotic cells and IgG-opsonized target cells. Br J Haematol 142: $469-479$.

Zhao XW, Gazendam RP, Drewniak A, van Houdt M, Tool AT, van Hamme JL, Kustiawan I, Meijer AB, Janssen H,
Russell DG, et al. 2013. Defects in neutrophil granule mobilization and bactericidal activity in familial hemophagocytic lymphohistiocytosis type 5 (FHL-5) syndrome caused by STXBP2/Munc18-2 mutations. Blood 122: 109-111.

Zuccato E, Blott EJ, Holt O, Sigismund S, Shaw M, Bossi G, Griffiths GM. 2007. Sorting of Fas ligand to secretory lysosomes is regulated by mono-ubiquitylation and phosphorylation. J Cell Sci 120: 191-199.

zur Stadt U, Schmidt S, Kasper B, Beutel K, Diler AS, Henter JI, Kabisch H, Schneppenheim R, Nurnberg P, Janka G, et al. 2005. Linkage of familial hemophagocytic lymphohistiocytosis (FHL) type-4 to chromosome 6q24 and identification of mutations in syntaxin 11. Hum Mol Genet 14: 827-834.

zur Stadt U, Rohr J, Seifert W, Koch F, Grieve S, Pagel J, Strauss J, Kasper B, Nurnberg G, Becker C, et al. 2009. Familial hemophagocytic lymphohistiocytosis type 5 (FHL-5) is caused by mutations in Munc18-2 and impaired binding to syntaxin 11. Am J Hum Genet 85: 482-492. 


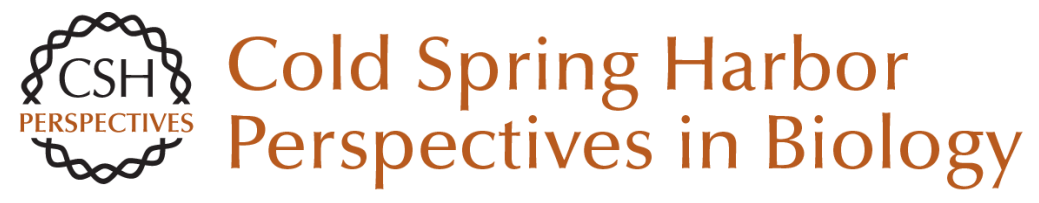

\title{
The Biogenesis of Lysosomes and Lysosome-Related Organelles
}

\author{
J. Paul Luzio, Yvonne Hackmann, Nele M.G. Dieckmann and Gillian M. Griffiths
}

Cold Spring Harb Perspect Biol 2014; doi: 10.1101/cshperspect.a016840

\section{Subject Collection Endocytosis}

\section{Endocytosis: Past, Present, and Future} Sandra L. Schmid, Alexander Sorkin and Marino Zerial

Rab Proteins and the Compartmentalization of the Endosomal System

Angela Wandinger-Ness and Marino Zerial

Cargo Sorting in the Endocytic Pathway: A Key Regulator of Cell Polarity and Tissue Dynamics Suzanne Eaton and Fernando Martin-Belmonte

Unconventional Functions for Clathrin, ESCRTs, and Other Endocytic Regulators in the

Cytoskeleton, Cell Cycle, Nucleus, and Beyond:

Links to Human Disease

Frances M. Brodsky, R. Thomas Sosa, Joel A. Ybe, et al.

Endocytosis of Viruses and Bacteria Pascale Cossart and Ari Helenius

Lysosomal Adaptation: How the Lysosome

Responds to External Cues Carmine Settembre and Andrea Ballabio

Reciprocal Regulation of Endocytosis and Metabolism

Costin N. Antonescu, Timothy E. McGraw and Amira Klip

Endocytosis and Autophagy: Exploitation or Cooperation?

Sharon A. Tooze, Adi Abada and Zvulun Elazar
Imaging and Modeling the Dynamics of

Clathrin-Mediated Endocytosis

Marcel Mettlen and Gaudenz Danuser

Endocytic Accessory Factors and Regulation of

Clathrin-Mediated Endocytosis

Christien J. Merrifield and Marko Kaksonen

The Complex Ultrastructure of the Endolysosomal

System Judith Klumperman and Graça Raposo

The Biogenesis of Lysosomes and

Lysosome-Related Organelles

J. Paul Luzio, Yvonne Hackmann, Nele M.G.

Dieckmann, et al.

Endocytosis, Signaling, and Beyond Pier Paolo Di Fiore and Mark von Zastrow

Clathrin-Independent Pathways of Endocytosis Satyajit Mayor, Robert G. Parton and Julie G. Donaldson

The Role of Endocytosis during Morphogenetic Signaling Marcos Gonzalez-Gaitan and Frank Jülicher

Role of Endosomes and Lysosomes in Human Disease

Frederick R. Maxfield

For additional articles in this collection, see http://cshperspectives.cshlp.org/cgi/collection/

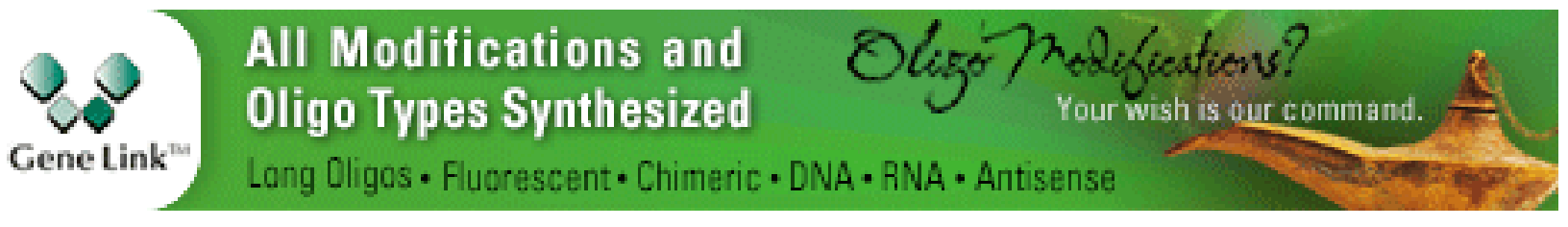


For additional articles in this collection, see http://cshperspectives.cshlp.org/cgi/collection/

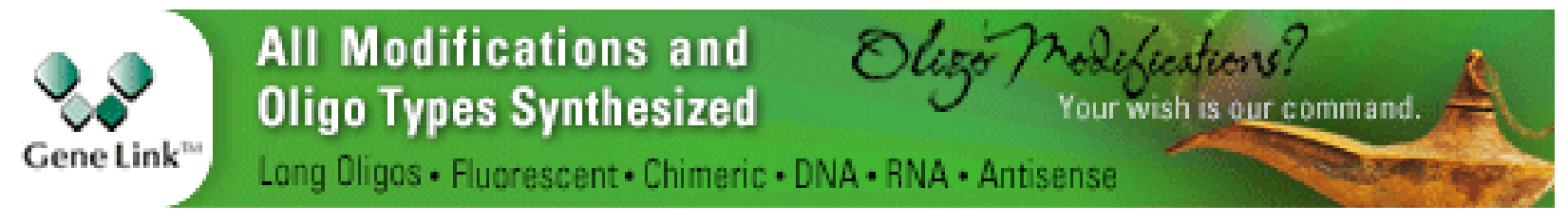

Copyright @ 2014 Cold Spring Harbor Laboratory Press; all rights reserved 